INTEGRATING LITERACY AND ENGINEERING INSTRUCTION FOR YOUNG LEARNERS

\author{
Amy Wilson-Lopez and Stacie Gregory
}

Amy Wilson-Lopez is an assistant professor of education at Utah State University, Logan, UT, USA; amyalexandra.wilson@usu.edu.

Stacie Gregory is a doctoral student of engineering education at Utah State University, Logan, UT, USA: staciegregory2@gmail.com.

Submission Type: Article. 
Teaser Text: Reading and writing are the perfect partners to innovating and building. This article describes how literacy can be used to enhance creativity, reflection, and analysis in engineering.

\section{Integrating Literacy and Engineering Instruction for Young Learners}

Every day, millions of people phone loved ones, take medicines to ease pain, or simply fill a glass with safe drinking water from a faucet. Countless examples such as these illustrate how engineering has profoundly enriched and enhanced people's quality of life on many levels. Children, too, can be introduced to the practices of this discipline from an early age as they seek for innovative ways to meet people's needs or solve problems. In fact, at least 41 states include standards that relate to engineering, often beginning at the elementary level (Carr, Bennett, \& Strobel, 2012), and the Next Generation Science Standards (Achieve Inc., 2014) have asserted that elementary students can and should develop engineering-based skills and competencies.

Although engineering competencies are now required as part of national standards, many elementary teachers feel uncomfortable with teaching engineering, especially because their instructional time is already limited (Duncan, Diefes-Dux, \& Gentry, 2011). However, engineering units need not detract from time spent with reading high-interest texts, from time spent on comprehension strategy instruction, or from time spent in writing. In fact, we argue that literacy instruction and national elementary-level engineering standards are mutually complementary and reinforcing (see Table 1). That is, students can practice writing and applying comprehension strategies in ways that help them to become more thoughtful engineers, and they can practice engineering design activities in ways that help them to become more experienced readers and writers. 
In this article, the authors - one of whom specializes in literacy and the other of whom is a professional engineer - offer suggestions for incorporating engineering and literacy instruction with upper elementary students. These suggestions are based in previous research literature (Wilson, Smith, \& Householder, 2014), in national science standards (Achieve Inc., 2014), and in our experiences with co-teaching monthly literacy-infused engineering units in third- and fifth-grade classrooms.

Insert Table 1 about here.

\section{How Can Literacy Instruction Enhance Engineering Activity?}

Researchers (e.g., Moje, 2008; Shanahan \& Shanahan, 2008) have argued that the end goal of disciplinary literacy instruction is not to produce better generic readers and writers, but instead to cultivate discipline-specific habits of mind and practices. Even young elementary students can learn to act and think in accordance with the norms of each content area (Shanahan \& Shanahan, 2014). Within the discipline of engineering, one central activity is design, which can be defined as "a systematic, intelligent process in which designers generate, evaluate, and specify concepts for devices, systems, or processes whose form and function achieve clients' objectives or users' needs while satisfying a specified set of constraints" (Dym et al., p. 104). Accordingly, we sought to provide literacy instruction that fostered students' abilities to engage in design activity, an instructional approach that is consistent with recommendations to embed literacy instruction within authentic disciplinary tasks (Parsons \& Ward, 2011).

Dozens of engineers and K-12 educators have described design processes, or stages of activity that youth can use to create or improve products that meet people's needs (Dym \& Little, 
2009). Although these authors offer different descriptions of engineering design processes, they all share common elements (Mehalik \& Schunn, 2006; see Figure 1). These elements are nonlinear as students repeatedly return to any given stage multiple times while they think through their designs. In the following descriptions, we draw from our experiences in implementing several engineering units with different classes to illustrate how literacy instruction can be used to support students in successfully applying engineering design processes. These components of literacy instruction include careful selection of children's or young adult literature, comprehension strategy instruction, and using writing as a learning tool.

Insert Figure 1 about here.

\section{Selecting Texts for Literacy-Infused Engineering Units}

On a fundamental level, engineering begins with a problem that needs to be solved (Bybee, 2011). Although most narratives feature protagonists who face some kind of conflict, a defining feature of texts used in our engineering units was that the characters' problems could be solved through building a device, creating a product, and/or implementing a series of processes or steps. For instance, fifth-graders read excerpts from Candy Bomber: The Story of the Berlin Airlift's “Chocolate Pilot” (O’Tunnell, 2010), a biography written for a young adult audience. In this text, O'Tunnell told the story of Lt. Halvorsen, a pilot who sought to provide candy to starving children living in Berlin, Germany immediately after World War Two. The city, however, was blockaded and Halvorsen was sure his commanding officers would not allow him to carry candy in the food crates that he flew into the city. To help the protagonist with this 
problem, the fifth-graders conceptualized several devices that they believed would have enabled him to deliver candy safely to the children as he flew over them.

As a second example, third-graders read Oil Spill! (Berger, 1994), an informational text that used child-friendly language and large illustrations to describe the devastating effects of the Exxon Valdez tanker's collision with an underwater reef off of the coast of Alaska. Students sought to address the problem through a series of sequenced steps as they decided whether they should first contain the oil or try to start cleaning it; whether they should scoop out the oil first, and then soak up the remaining oil, or soak up oil first and then scoop out the remaining oil next; and so forth. As suggested by these examples, one important initial step for planning literacyinfused engineering units includes choosing texts that introduce particular kinds of problems.

We used three criteria for selecting texts with engineering-based problems. First, we asked ourselves whether it held the potential to interest our particular students. For instance, we chose Candy Bomber in part because Gail Halvorsen lived in the same region as the students whom we taught, and many of them had heard him speak at religious conferences. We chose Oil Spill! in part because one third-grade student had recently moved from Alaska, and we used the story as a springboard for her to share her experiences with the environment there. When possible, elementary teachers can select texts for engineering units in part because they align with students' interests; resonate with their linguistic, cultural, or geographic backgrounds; and/or introduce them to problems that they have witnessed in their homes or communities.

Second, we selected texts that were accessible to young readers. These texts included features, such as illustrations and explanations of difficult vocabulary words, which specifically targeted children or young adults. Third, we selected texts that would help students meet state social studies or science standards. In this case, we chose the problem of dropping candy in order 
to meet the Next Generation Science Standards for fifth grade, as students learned that "the gravitational force of Earth acting on an object near Earth's surface pulls that object toward the planet's center" (5-PS2-1). Although Candy Bomber did not introduce this scientific principle directly, we supplemented it with a high-interest trade book, Forces Make Things Move (Bradley, 2005), which explained how gravity is a force that pulls objects towards the Earth.

In the case of Oil Spill!, we reasoned that a discussion of the spill's effect on the animals in the environment would support students in meeting the third-grade NGSS by explaining how "populations live in a variety of habitats, and change in those habitats affects the organisms living there" (3-LS4-4). Because engineers also often interpret visual information, we further supplemented both units with visual texts, such as maps of each area and photographs of existing devices designed to address similar problems.

Table 2 offers examples of other books we found in which fictional or actual characters faced problems that could be solved through engineering. We offer this list to spark ideas for teachers who seek to find their own informational, biographical, or historical fictional texts to introduce engineering-related problems to students. The vignette below demonstrates how several of these types of texts were used to introduce fifth-grade students to a problem that could be solved through engineering.

Insert Table 2 about here.

After students share what they know about the end of World War Two, the teacher displays a map on the board showing how Germany was divided among four countries 
after the war (Rosmanitz, 2013). She models for students how to summarize visual information and how to ask clarification questions about visual texts. For instance, based on students' input, she annotates the map with a summary, "The US, the USSR (Russia), France, and Great Britain each got a piece of Germany after World War Two."

Students work in small groups to continue annotating their own individual maps by asking questions or summarizing their observations. One group, for example, writes, "Why did all four countries divide that city [Berlin]?" while another writes, "Berlin is in the area owned by Russia." After discussing their questions and summaries, the teacher continues the lesson by noting that the true story they will read takes place in Berlin, where the USSR prevented food from entering American, British, and French territories.

Students make predictions about what they think the countries will do, such as "All three of the places will all use planes to send food crates." They then read excerpts from The Candy Bomber in small groups. They stop at pre-determined points; annotate the text with summaries, questions, and predictions; and discuss their annotations. At an appointed place in the text, the small groups share their summaries with the class as the teacher writes a collective summary on the board: "Lt. Halvorsen wanted to fly candy to the children in Berlin, but his commanding officer would not give him permission to carry it in the regular food crates, and dropping packages from planes would be dangerous."

"You just identified the problem we will have to solve as engineers," the teacher notes. "What do you predict Lt. Halvorsen could to do to solve the problem?" At this point, the students share their predictions about what he could do, such as wrapping the candies in cotton balls or pillows and dropping them, attaching the candies to very long 
ropes and dropping the ropes so the children could reach the candies above their heads, dropping candies in little hot air balloons that gradually lose pressure as they land, and placing the candies in cups attached to parachutes. The teacher praises them for brainstorming solutions to a problem, which is part of engineering, but says that engineers sometimes have constraints on what they can do, or limitations they have to consider, such as only having a certain amount of money they can spend or only having certain materials available.

The teacher then displays the photograph from Figure 2, and students make inferences about the materials that Lt. Halvorsen had available to him for delivering the candy to the children. They recall that people were poor and lands were destroyed after the war. In light of this information, they revise their initial predictions by stating that Lt. Halvorsen would not have access to many types of materials, but he would have access to the cloth and string featured in the photograph. The teacher responds by stating that the students will work within similar constraints by only using a limited set of materials when they build their own devices to help the candies land safely.

Insert Figure 2 about here.

To address grade-level science standards, the teacher later continues: "Let's go back to the line that says, "One package, though not large...would be a dangerous missile." Let's think about that. If I drop this package of candy on your hands [stands on a chair and demonstrates dropping candy on a student's hands], does that hurt? How could candy become a dangerous missile?" 
"It would kill him," responds one student.

"Why would it kill him?" the teacher rejoins. "If the candy drops from the plane or from the chair, the weight of the candy stays the same and your body stays the same. So why would the candy hurt him if it drops from the airplane and not the chair?"

"It kind of has more force."

"Why does it have more force? That's exactly the word I'm looking for."

"It's going faster, so when it hits, it hits harder."

"The gravity would pull it down," responds another student.

Students then read a brief excerpt about gravity from Forces Make Things Move (Bradley, 2005) and discuss how the gravity would pull candy toward the earth, causing it to accelerate or speed up as it falls downward. The teacher introduces the equation, force $=$ mass $x$ acceleration, to explain that the more an object is accelerating, the more force it will have, even if the object's mass stays the same. She then asks students to brainstorm ideas that Halvorsen could use to slow the candy's acceleration.

One student argues, "I think he should make a parachute really wide, so it can catch more air, so it can fall really slowly." Based on this student's comment, the teacher agrees that parachutes increase air resistance as air pushes up on the parachute, which acts as a counter-force to gravity. She encourages the student to test his assumption that the wider a parachute is, the more slowly it will fall, or the more air resistance it will produce, when they build and test their parachutes later.

Finally, students view photographs of various kinds of parachutes on the interactive whiteboard, and they note the differences among them: differences in shape and area of parachute, material, number of strings, and length of strings to name a few. 
Students identify which parachute they think would result in the most air resistance, or that would drop the candy to the ground most slowly, and explain why.

\section{Comprehension Strategy Instruction and Engineering Design Processes}

In addition to demonstrating how visual, informational, and biographical texts can work together to introduce engineering problems, this vignette also demonstrates how comprehension strategy instruction (CSI) on children's literature can complement and reinforce engineering design processes. In this lesson, the teacher practiced one component of CSI by explicitly naming and modeling two comprehension strategies for students — summarizing and asking questions - as well as enforcing other comprehension strategies that students had practiced throughout the year, such as predicting and inferring (Block \& Pressley, 2002). After teacher modeling, students gained practice with applying these strategies more independently through annotating or discussing the map, the informational text, and the photograph.

At the same time, in addition to reinforcing strategic reading, the application of these comprehension strategies also reinforced engineering habits of mind. For instance, what Amy (a literacy specialist) viewed as summarizing — such as the statement "Lt. Halvorsen wanted to fly candy in to the children in Berlin, [but] dropping packages from planes would be dangerous"Stacie (an engineer) viewed as problem scoping, or identifying a need or a problem. What Amy viewed as predicting — such as making conjectures about what Lt. Halvorsen would or could do to solve the problem-Stacie viewed as part of the initial process of developing solutions, or brainstorming ideas that would help solve the problem or meet the need.

Lastly, what Amy viewed as inferring — such as using the picture to draw evidence-based conclusions about available materials - Stacie viewed as problem scoping, or identifying constraints, which students later used to evaluate the feasibility of their previous suggestions. In 
this case, the students inferred that Lt. Halvorsen was constrained by materials available in wartorn Germany, and it was probably unrealistic to expect that he would own miles-long ropes from which he could dangle the candy.

In implementing other literacy-infused engineering units with elementary students, we found that students often applied engineering design processes as part of the natural course of comprehension strategy instruction. For instance, before reading Oil Spill! with the third graders, the teacher modeled how to make predictions and then encouraged students to independently practice the strategy while reading. The third-graders made predictions about what the environmental engineers in the story would and should do next to solve their problem, much as the fifth-grade students predicted what Halvorsen would do next to solve his problem. For instance, one third-grader predicted that after the oil began to leak, the engineers would "put a rope or something around the water that can float so you can trap the oil.”

As an engineer, Stacie identified these predictions as problem scoping and developing solutions, in the sense that this student defined the problem by prioritizing the actions that the engineers should take, and then he offered a suggestion to the engineers in accordance with this priority. In his opinion, the engineers' first priority was to "trap the oil" or contain the spill, and accordingly, his suggested course of action was to put a rope around the affected water. Other students held different priorities, and they predicted that the engineers' first course of action should be to clean (not contain) the water. Callie, for instance, knew that "water and oil don't mix cause it [oil] stays on top, and you can kind of lift it off the water...[so] we could get a vacuum." Manuel agreed, "We could take a large container and try to scoop it up," while David wondered, "Why don't they put it on fire?" 
In addition to predicting what the engineers would or should do, the students also made inferences about which solutions were best. In other words, the comprehension strategy of inferring also helped students to evaluate solutions. For instance, upon reading the section where environmental engineers could opt to set the oil on fire or pump it out of the water, Chelsea inferred that the pumping option was better because "they could re-use the oil." As suggested by these examples, the third-grade students' discussions surrounding the text, conducted within the context of comprehension strategy instruction, engaged them in the types of thinking practiced by environmental engineers.

In sum, practicing comprehension strategies with carefully-selected texts is one way to help students engage in engineering design processes (cf. Wilson, Smith, \& Householder, 2014). Summarizing the text can help students to review and define the problem; asking questions can help students to clarify aspects of the problem that are still confusing; predicting can help students generate ideas in relation to the problem; and inferring can help students to evaluate solutions or to identify constraints inherent in the situation, which are oftentimes left implicit (Dym \& Little, 2009).

\section{Writing-to-Learn in Literacy-Infused Engineering Units}

Because students' disciplinary writing often improves after they have evaluated exemplar texts as models (Pytash \& Morgan, 2014), we shared and discussed professional Engineers' Notebooks with students. These notebooks illustrated how engineers record and evaluate their ideas through writing, drawing, and mathematical calculations. We then provided each student with an Engineer's Notebook. We continue the vignette below to describe how students used their notebooks as an integral part of the aerospace engineering (parachute) unit. 
The teacher announces that students will build and test their own parachutes as Lt. Halvorsen did. She asks them what the most important characteristics of those parachutes should be, and they unanimously agree that the most important characteristic is that they should drop the candy to the ground safely. A student suggests that another important characteristic is that the parachutes should be made out of inexpensive materials. Although many items were rationed after WWII, the class brainstorms lists of possible materials they might use, and they decide on string, squares of cloth, and various kinds of paper.

Working within these constraints, students collaborate in partners to draw a design for their own parachute that they believe would maximize air resistance. Instructions on the board ask students to label different aspects of their parachute (e.g., size of parachute, length of string, types of material they will use) and to explain why they think their proposed parachute will slow the candy's fall by increasing air resistance.

A week later, students test their proposed designs. The teacher distributes the rubric she created based on the two criteria that the students stated were important, and students paste these rubrics into their Engineers' Notebooks. The teacher clarifies that the candy must drop at a rate of five feet per second or slower in order to be considered safe. In their notebooks, students calculate how slowly their candy should drop from the school balcony, given that it is about 17 feet tall.

Each partnership then constructs a small parachute and drops it to the ground from the balcony as an adult notes their time using a stopwatch. Students record their time in their Engineers' Notebooks as well as on a chart on the whiteboard; then they choose one aspect of their design they want to change to make their second parachute 
drop more slowly. For instance, one partnership chooses a lighter type of paper, rather than cloth, for their second parachute, while another partnership chooses to increase the area of their parachute. Once again, they record their times in their notebooks and on the board.

Following the activity, the students whose parachutes dropped the candy the most slowly explain why they thought their design worked so well. For instance, one partnership explains, "We have a lot of area, and the parachute itself is paper. It went slow because of more area on the parachute, and it weighed less [than cloth]."

After further discussion regarding why some parachutes dropped quickly while others dropped slowly, students then evaluate their final design according to the rubric, write why they thought their design worked the way that it did (e.g., why it dropped quickly or slowly), and state what they might do differently next time if they were to improve their parachutes. To guide the students' writing, the teacher provides them with a list of possible sentence beginnings they can use, as well as discussing a few models of statements that are supported by reasoning versus those that are not supported by reasoning.

Much as writing is central to scientific inquiry and is part of the "process that leads to the construction of knowledge" (Chen, Hand, \& McDowell, 2013 p. 748), writing served an important role in engineering units by guiding students as they generated knowledge about why some design elements might work better than others.

As suggested by this vignette, different types of writing served different roles in facilitating students' design work. First, students used writing as a thinking tool when they brainstormed a list of criteria their design should meet (e.g., the candy should fall safely to the 
ground and the parachute should be made out of inexpensive materials). The students also used writing to record their ideas with the intention of returning to them later, such as when they drew and labeled pictures of parachutes. They used writing to record data from observations, such as when they recorded the time that each parachute took to fall to the ground. Finally, they used writing as a reflective tool when they evaluated how well their design worked and speculated on why it worked that way. These purposes for writing are authentic to professional engineers' work as well (Kelley, 2011).

We integrated writing into each of our other engineering units in similar ways and for similar purposes. For instance, for a unit in which students designed and tested water filters, students first evaluated how well individual materials — such as cheesecloth, sand, and coffee filters - cleaned water. They used data charts to rank each material on a scale from 1-10 and explain why they gave it the ranking that they did. They then used this information to determine how they might combine and order materials together when they constructed their own water filter. They again used writing to list what the most important criteria for a successful design would be, such as that the water would appear clear and it would not include visible chunks in it, and they used writing to evaluate how well their final designs met these criteria.

In all, we found that it was easy to integrate various types of writing into engineering units in ways that were authentic to engineering design work. These forms of writing included informal writing that enabled students to reason through ideas. These forms of writing also included more structured writing — for which we provided models — in which students evaluated their designs or explained why some designs worked better than others. 


\section{Conclusion}

Engineering - the "E" in STEM education — has traditionally been paired with science, technology, and mathematics, but reading and writing are also natural partners to this discipline. As suggested by this article, literacy instruction can be used to facilitate in-depth thinking about engineering problems throughout multiple stages of the design process. In the words of one dean of a nationally regarded College of Engineering: "Reading and writing make our students better readers, better writers, better thinkers, and better engineers" (C. Hailey, personal communication, November 17, 2011). Although she was talking about college students, we argue that literacy instruction enhances elementary students' engineering design as well while preparing young people to engage in disciplinary activity that can make a difference in the quality of life for others. 


\section{References}

Achieve, Inc. (2014). Next generation science standards. Retrieved from http://www.nextgenscience.org/next-generation-science-standards

Block, C.C., \& Pressley, M. (Eds.). (2002). Comprehension instruction: Research-based best practices. New York, NY: Guilford.

Bybee, R.W. (2011). Scientific and engineering practice in K-12 classrooms. Science Teacher, 78(9), 34-40.

Carr, R.L., Bennett, L.D., \& Strobel, J. (2012). Engineering in the K-12 STEM standards of the 50 U. S. States: An analysis of presence and extent. Journal of Engineering Education, $101(3), 1-26$.

Chen, Y-C., Hand, B., \& McDowell, L. (2012). The effects of writing-to-learn activities on elementary students' conceptual understanding: Learning about force and motion through writing to older peers. Science Education, 97(5), 745-771.

Duncan, D., Diefes-Dux, H., \& Gentry, M. (2011). Professional development through engineering academies: An examination of elementary teachers' recognition and understanding of engineering. Journal of Engineering Education, 100(3), 520-539.

Dym, C.L., Agogino, A.M., Eris, O., Frey, D.D., \& Leifer, L.J. (2005). Engineering design thinking, teaching, and learning. Journal of Engineering Education, 94(1), 103-120.

Dym, C.L., \& Little, C.L. (2008). Engineering design: A project based introduction ( $3^{\text {rd }}$ ed.). New York, NY: Wiley.

Kelley, T.R. (2011). Engineers' notebook: A design assessment tool. Technology \& Engineering Teacher, 70(7), 30-35. 
Mehalik, M.M., \& Schunn, C. (2006). What constitutes good design? A review of empirical studies of design processes. International Journal of Engineering Education, 22(3), 519532.

Moje, E.B. (2008). Foregrounding the disciplines in secondary literacy teaching and learning: A call for change. Journal of Adolescent \& Adult Literacy, 52(2), 96-107.

Parsons, S.A., \& Ward, A.E. (2011). The case for authentic tasks in content literacy. The Reading Teacher, 64(6), 462-465.

Pytash, K.E., \& Morgan, D.N. (2014). Using mentor texts to teach writing in science and social studies. The Reading Teacher. DOI: 10.1002/trtr.1276

Rosmanitz, K. (2013). Results and aftermath of World War II. Retrieved from http://www.english-online.at/history/world-war-2/results-and-aftermath-of-world-warii.htm

Shanahan, C., \& Shanahan, T. (2014). Does disciplinary literacy have a place in elementary school? The Reading Teacher, 67(8), 636-639.

Shanahan, T., \& Shanahan, C. (2008). Teaching disciplinary literacy to adolescents: Rethinking content area literacy. Harvard Educational Review, 78(1), 40-59.

Wilson, A.A., Smith, E., \& Householder, D. L. (2014). Using disciplinary literacies to enhance adolescents' engineering design activity. Journal of Adolescent \& Adult Literacy, 57(8), 676-686. 


\section{Literature Cited}

Beaty, A. (2007). Iggy Peck, architect (Illus. D. Roberts). New York, NY: Abrams Books for Young Readers.

Berger, M. (1994). Oil Spill! (Illus. P. Mirocha). New York, NY: HarperCollins.

Bradley, K.B. (2005). Forces make things move (Illus. P. Meisel). New York, NY:

HarperCollins.

Ellis, J. (2010). Pythagoras and the ratios: A math adventure (Illus. P.H. Peacock). Watertown, MA: Charlesbridge.

Hollyer, B. (2008). Our world of water: Children and water around the world. New York, NY: Henry Holt.

Kambkwamba, W., \& Mealer, B. (2012). The boy who harnessed the wind (Illus. E. Zunon). New York, NY: Dial Books for Young Readers.

Logan, C. (2002). The 5,000 year old puzzle: Solving a mystery of ancient Egypt (Illus. M. Sweet). New York, NY: Farrar, Straus and Giroux.

O'Tunnell, M. (2010). Candy bomber: The story of the Berlin airlift's "Chocolate Pilot." Watertown, MA: Charlesbridge.

Polacco, P. (2014). Clara and Davie: The true story of young Clara Barton, founder of the American Red Cross. New York, NY: Scholastic.

Stainton, S. (2004). Lighthouse cat (illus. A. Mortimer). New York, NY: HarperCollins.

Torheim, M.G. (2014). Solar-powered bread baking in Ethiopia. Retrieved from: http://sciencenordic.com/solar-powered-bread-baking-ethiopia 


\section{More to Explore}

Abts, L. (2011). Engineering design process portfolio scoring rubric. Retrieved from: https://innovationportal.org/resources/edppsr-download

Sneider, C.I. (Ed.). (2014). The go-to guide for engineering curricula, pre-K-5: Choosing and using the best instructional materials for your students. Thousand Oaks, CA: Corwin.

WGBH Educational Foundation. (2014). Design squad nation: Teacher's guide. Retrieved from: http://pbskids.org/designsquad/parentseducators/guides/teachers_guide.html 
Table 1

Grades 3-5 Next Generation Science Standards with Associated Literacy Instruction

NGSS Engineering Standard

3-5-ETS1-1. Define a simple design problem reflecting a need or a want that includes specified criteria for success and constraints on materials, time, or cost.
Literacy Instruction

Read a text that introduces a problem which can be solved through engineering. Help students understand the text and the parameter of the problem through applying comprehension strategies such as inferring, summarizing, and predicting.
3-5-ETS1-2. Generate and compare multiple possible solutions to a problem based on how well each is likely to meet the criteria and constraints of the problem.
Use mentor texts, or models of existing writing, to demonstrate: how to record initial ideas, including through lists and through labeled pictures. how to evaluate problems according to specified criteria and constraints, including through writing responses to rubrics. -how to record data relevant to criteria and constraints, including through tables.

As the year progresses, provide students with opportunities to independently produce their own texts after they have discussed these models.
3-5-ETS1-3. Plan and carry out fair tests in which variables are controlled and failure points are considered to identify aspects of a model or prototype that can be improved.
Teach students how to support their claims or predictions with reasons and evidence in their writing. 
Table 2

Examples of Texts in Which Characters Can Solve Problems through Engineering

Title and Genre $\quad$ Problem Faced by Design Challenge Connection to Science or Character Social Studies

The 5,000 Year-Old Young Will Hunt is part

Puzzle: Solving a

Mystery of Ancient

Egypt (Logan, 2002). Historical fiction. of an expedition that has uncovered an Egyptian tomb in 1924 , but he needs some means of lighting it without harming any of the artifacts.
Shine a flashlight on mirrors positioned in a box (representing the tomb) to try to illuminate specific parts of the box.
Science: Light travels in straight lines and reflects off of certain surfaces.

Social Studies:

Archaeology is one way that people learn about life in the past.

\begin{tabular}{|c|c|c|}
\hline $\begin{array}{l}\text { The Boy Who } \\
\text { Harnessed the Wind } \\
\text { (Kamkwamba \& } \\
\text { Mealer, 2012). } \\
\text { Biographical }\end{array}$ & $\begin{array}{l}\text { William Kamkwamba's } \\
\text { village is facing a } \\
\text { drought, and he must find } \\
\text { a way to pump water out } \\
\text { of the ground. }\end{array}$ & $\begin{array}{l}\text { Build a model } \\
\text { windmill that, when } \\
\text { placed in front of a } \\
\text { fan, can lift weights in } \\
\text { a cup. }\end{array}$ \\
\hline
\end{tabular}

The Boy Who
Science: Compare and contrast renewable energy sources and non-renewable energy sources.

Social Studies: Introduce geography and cultures of regions in Eastern Africa.
Clara and Davie:

The True Story of

Young Clara Barton,

Founder of the

American Red Cross

(Polacco, 2014).

Historical fiction.
Clara's brother Davie falls from a roof beam in the barn and breaks both of his legs. Clara nurses him back to health and is later inspired to found the Red Cross.
Build braces that immobilize the legs of action figures or dolls while still enabling the patients to feel comfortable.
Science: Explain the function of joints. Observe (and limit) the types of movement enabled by different joints.

Social Studies: Describe how people have sought to improve their communities or work for the public good.
Iggy Peck, Architect (Beaty, 2007).

Fictional narrative.
Iggy Peck's elementary class crosses a small footbridge in order to hold a picnic on a small island in the middle of a stream. Right after they cross, the footbridge collapses, and the class must figure out a way to get back.
Use available materials to construct a bridge that will hold a specified amount of weight.
Science: Examine how objects in contact exert forces on each other.

Social Studies: Discuss how innovation and new technologies-including those related to transportation-can improve life for individuals and for groups. 
Table 2 (continued)

Title and Genre

Lighthouse Cat

(Stainton, 2004).

Fictional narrative.
Problem Faced by

Character

The lights in the

lighthouse are snuffed out

during a fierce storm

while a nearby boat

signals distress.
Design Challenge

Use electrical circuits

to build a lighthouse

that illuminates the

area surrounding it.
Pythagoras and his

friends want to form a music band, but their instruments are out of tune. Pythagoras must find a way to make the instruments sound pleasing.
Build a musical instrument (such as wooden sticks tapping on glasses of water) whose proportions produce harmonious sounds.
Connection to Science or Social Studies

Science: Explore how electrical energy can be transferred from place to place by electric currents. Social Studies: Explain how people, goods, and ideas have moved from place to place at different periods in history.
Adventure (Ellis, fiction.
Each vignette describes one boy or girl in a different region of the world who obtains water using different means, including carrying buckets of water from a pond or collecting water from rain gutters on roofs.
Construct a water filter to help the children clean their water.
Informational vignettes.
Our World of Water: Around the World.
Science: Examine how vibrating matter can make sound.

Social Studies: Introduce the culture of ancient Greece and its contributions to modern societies.
Science: Identify the importance of water conservation after describing amount of freshwater on earth. Social Studies: Identify how features such as local landforms (e.g., glaciers) and weather patterns (e.g., lack of rain) influence daily life.

$\begin{array}{lll}\begin{array}{l}\text { Solar-Powered } \\ \text { Bread Baking in }\end{array} & \begin{array}{l}\text { Many people in Ethiopia } \\ \text { lack access to electric }\end{array} & \begin{array}{l}\text { Build a solar oven that } \\ \text { can bake a pizza or }\end{array} \\ \begin{array}{l}\text { Ethiopia } \text { (Torheim, } \\ \text { 2014). Informational }\end{array} & \begin{array}{l}\text { power and firewood. } \\ \text { Asfafaw Tesfay }\end{array} & \begin{array}{l}\text { melt chocolate and } \\ \text { marshmallows to } \\ \text { text. }\end{array} \\ & \begin{array}{l}\text { developed a solar oven } \\ \text { that enables Ethiopians to } \\ \text { bake bread using energy } \\ \\ \end{array} & \\ & \text { from the sun. }\end{array}$

Solar-Powered Bread Baking in Ethiopia (Torheim, 2014). Informational from the sun.
Science: Energy can be converted from one form into another, such as from light into heat.

Social Studies: Explain how environmental characteristics (e.g., absence of forests) affect people's lives in a given region. 


\section{Take Action!}

1. Even if you don't have a professional engineer in your classroom, there are many resources to help you integrate engineering into your curriculum. The National Science Foundation has compiled a list of online resources for K-12 teachers who wish to teach engineering at: http://www.nsf.gov/news/classroom/engineering.jsp. The Engineering Is Elementary website may also be helpful: http://www.eie.org/. For models of engineers' notebooks you might use, visit http://www.sciencebuddies.org/engineering-design-process/engineering-designnotebook.shtml or type "engineering design notebook examples" into an Internet search engine.

2. Identify texts that introduce students to problems that could be solved through engineering projects, such as the types of projects identified in Step 1. Media specialists and others who are familiar with a wide range of children's literature may be helpful in brainstorming ideas for texts that introduce readers to problems in the physical world.

3. Model for students how a proficient reader might apply comprehension strategies when reading texts identified in Step 2. Pause your reading of the text at carefully chosen stopping points to enable students to independently apply those strategies. For instance, you may stop the text after the problem has been introduced to make predictions about ways the character might solve the problem as part of the "generating ideas" phase of the design process.

4. Display and discuss mentor texts that demonstrate to students what their own engineering texts might look like. These mentor texts could include charts that record data, drawings and explanations of their designs, and reflections on why their designs worked as they did.

\section{Pause and Ponder}

1. What possible engineering projects would meet science standards for the grade level that you teach? What search strategies can you use to find texts that would introduce those types of engineering projects to students?

2. Are you currently teaching any texts that include characters who face problems that could be solved through a device or set of processes? How might you introduce students to one or more aspects of the engineering design cycle as they are reading that text? 